\title{
Reliability Assessment for Corroded Pipelines in Series Considering Length-Scale Effects
}

\author{
Z. Mustaffa ${ }^{1}$, P. V. Gelder ${ }^{2}$, A. W. Dawotola ${ }^{3}$, S. Y. Yu ${ }^{1}$ and D. K. Kim ${ }^{1,4 *}$ \\ ${ }^{1}$ Department of Civil and Environmental Engineering, \\ Universiti Teknologi PETRONAS, Perak, Malaysia \\ ${ }^{2}$ Faculty of Technology, Policy and Management, TU Delft, Delft, Netherlands \\ ${ }^{3}$ Heneco Oil and Gas, Houston, Texas, USA \\ ${ }^{4}$ Graduate Institute of Ferrous Technology, POSTECH, Pohang, Republic of Korea \\ "Email: do.kim@utp.edu.my \\ Phone: +6053687312; Fax: +6053656716
}

\begin{abstract}
This paper presents a method for assessing the reliability of a corroded pipeline placed in series, with special consideration given to the effect of the length scale imposed by each segment of the pipe. The features of corrosion in different pipe segments are statistically correlated; thus, a failure in one section may impact the adjacent sections. Herein, using a correlation distance parameter, such statistical correlation is described considering the length-scale effects. The reliability of the corroded pipeline is presented in the form of a failure probability. The results show that analysing a corroded pipeline by considering length-scale effects produces a higher failure probability compared with the case where such effects are excluded, even when the parameters that govern corrosion in a pipeline are included in the analysis.
\end{abstract}

Keywords: Reliability; system; pipeline; series; corrosion.

\section{INTRODUCTION}

Probabilistic approaches are being increasingly adopted by various industries, in particular, the oil and gas industries, where cost optimisation is the key factor for achieving sustainability. A probabilistic approach allows the reliability of any operational structure to be estimated, including pipelines. A typical pipeline incurs high operational costs during its lifetime; thus, the associated costs of maintenance, repair, and replacement should be kept to a minimum without compromising safety. The easiest way to ensure both the safety and reliability of a pipeline is to prevent leaking from it. Most leaks are caused by thinning of the pipe wall, which usually results from corrosion and occasionally from erosion.

However, managing corrosion is problematic, especially for long pipelines laid in deep waters. A long pipeline is composed of many connected pipe segments, each 12 $\mathrm{m}$ long; therefore, a pipeline is best described as a serial structure. Utmost care should be taken when dealing with multiple segments or components because the failure of one can cause others to fail too. Because of its serial alignment, a pipeline may also be prone to effects associated with the length of its sections. Previous studies have investigated the effect of sectional length on structures operating in series, e.g., flood- and seadefence structures $[1,2]$. 
Therefore, this paper aims to investigate how length-scale effects manifest themselves in a pipeline and their impact on the overall failure probability of the structure. Figure 1 shows an example of a pipeline in which each section has a different failure probability $P_{f}$; it is noteworthy that the overall failure probability is greater than any of the sectional failure probabilities. Thus, it becomes problematic to specify the reliability of a corroded pipe precisely. This paper attempts to provide insights into determining the reliability in such cases. We also compare two pipeline reliability models: one with and the other without the influence of length-scale effects.

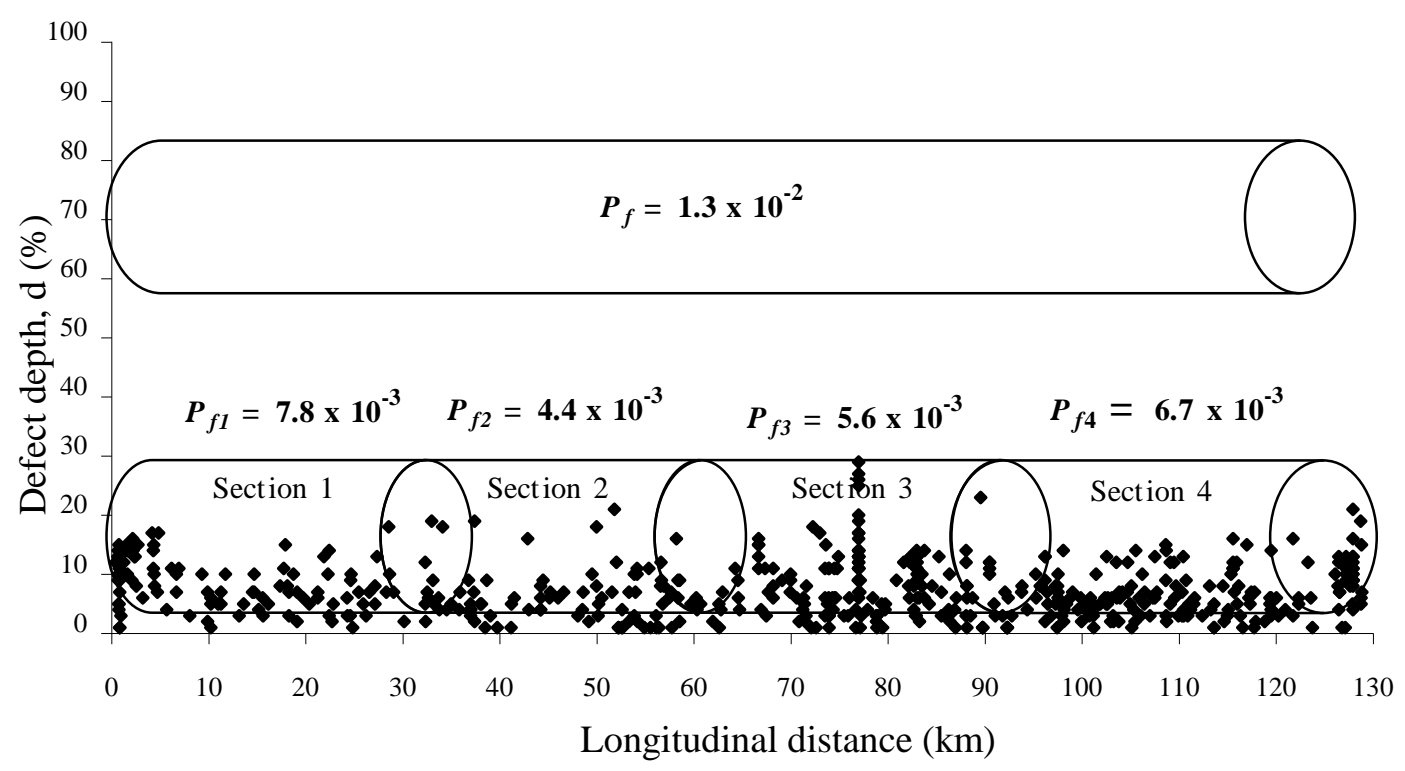

Figure 1. Variation in failure probability $P_{f}$ computed for different sections of a corroded API 5LX-65 pipeline.

\section{LITERATURE REVIEW}

\section{Reliability of System}

A system can be defined as "a group of elements or processes with a common objective" [3]. Many physical systems are composed of multiple components, and the reliability of a multicomponent system is a function of its redundancy [4]. If a system incorporates redundancy, its components can be either (i) participating [e.g., sharing loads (active redundancy)] or (ii) inactive until some other previously active component fails. Further details on this aspect may be referred to Ang and Tang [4]. A multicomponent system can be classified as being connected either in series or parallel.

\section{Serial system}

In a system whose components (elements) are connected in series (see Figure 2), failure of one or more components constitutes a failure of the entire system; therefore, serial systems have no redundancy and are also known as "weakest link" systems [4]. In other words, the reliability or safety of a serial system depends on none of its components failing. 


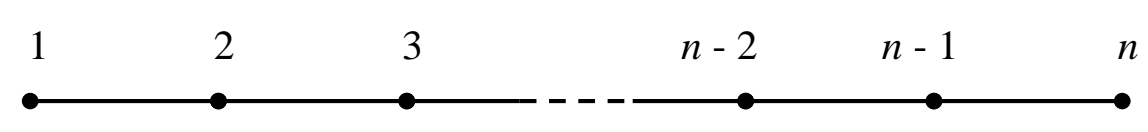

Figure 2. Representation of a serial system.

If $E_{i}$ denotes failure of component $i$, failure of a serial system comprising $m$ components, denoted by $E_{s}$, is the event;

$\mathrm{E}_{\mathrm{s}}=\mathrm{E}_{1} \cup \mathrm{E}_{2} \cup \ldots \cup \mathrm{E}_{\mathrm{m}}$

For a simple serial system that contains two components, the probability of component 1 failing (i.e., event $E_{1}$ ) or component 2 failing (i.e., event $E_{2}$ ) is given by:

$\mathrm{P}_{\mathrm{f}}=\mathrm{P}\left(\mathrm{E}_{1} \cup \mathrm{E}_{2}\right)=\mathrm{P}\left(\mathrm{E}_{1}\right)+\mathrm{P}\left(\mathrm{E}_{2}\right), \mathrm{P}_{\mathrm{f}}=\mathrm{P}\left(\mathrm{E}_{1}\right.$ or $\left.\mathrm{E}_{2}\right)$

Equation (2) shows that the probability of the system failing is a function of not only the probabilities of individual components failing but also of a conditional probability. This means that the statistical dependence of element failure is important [3].

\section{Parallel system}

In a system whose components or elements are connected in parallel shown in Figure 3, failure of the whole system requires the failure of all the components; in other words, if any one component survives, the system remains safe [4]. A parallel system is an obvious example of a system with redundancy. Failure of an $m$-component in a parallel system is denoted by the event. The probability of $n$ components failing in a parallel system is given by Eq. (4).

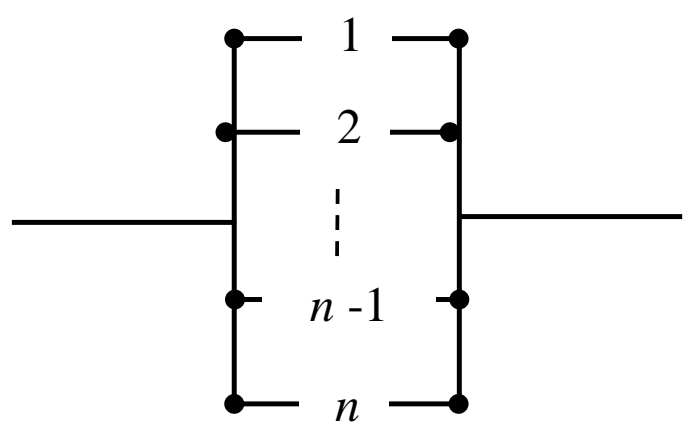

Figure 3. Representation of a parallel system.

$$
\begin{aligned}
& E_{s}=E_{1} \cap E_{2} \cap \ldots \cap E_{m} \\
& P_{f}=P\left(E_{1}\right) P\left(\frac{E_{2}}{E_{1}}\right) P\left(\frac{E_{3}}{E_{2}}, E_{2}\right) \ldots P\left(\frac{E_{n}}{E} \ldots . E_{n-1}\right)
\end{aligned}
$$




\title{
Background of Corrosion
}

\author{
Physics of $\mathrm{CO}_{2}$ corrosion
}

Corrosion is a chemical or electrochemical reaction between material, usually metal, and its environment that produces deterioration of the material and its properties. This is because of the natural tendency for most metals to return to iron in the presence of moist air. Corrosions are normally classified into two categories; the sweet and sour corrosions. The sweet corrosion is defined as the deterioration of metal caused by contact with carbon dioxide $\left(\mathrm{CO}_{2}\right)$ in water. The sour corrosion, on the other hand, containing or caused by hydrogen sulphide $\left(\mathrm{H}_{2} \mathrm{~S}\right)$ or another acid gas. The corrosion assessment presented in this paper is only concerned with sweet corrosion. Herein, the electrochemical process of $\mathrm{CO}_{2}$ corrosion involves the anodic dissolution of iron and cathodic evolution of hydrogen, as given below:

$\mathrm{Fe} \rightarrow \mathrm{Fe}^{++}+2 \mathrm{e}^{-}$

while the cathodic reactions are described by,

$2 \mathrm{H}^{+}+2 \mathrm{e}^{-} \rightarrow \mathrm{H}_{2}$

$2 \mathrm{H}_{2} \mathrm{CO}_{3}+2 \mathrm{e}^{-} \rightarrow \mathrm{H}_{2}+2 \mathrm{HCO}_{3}^{-}$

and finally, the overall reaction is then represented by,

$\mathrm{Fe}+\mathrm{CO}_{2}+\mathrm{H}_{2} \mathrm{O} \rightarrow \mathrm{FeCO}_{3}+\mathrm{H}_{2}$

\section{Forms of corrosion}

The electrochemical reactions between the metal and its environment would result in different forms of corrosion. While the most common one is pitting, others also include crevice, galvanic, intergranular, velocity- or microbially-induced corrosions, or even stress corrosion cracking and selective leaching as schematically shown in Figure 4 . The corrosion data analysed in this paper, however, were not limited to any forms of corrosions as the nature of the data captured by the inspection tool was inclusive of all. In the context of this paper, such inclusion would allow the overall geometries of corrosion developed in the pipe to be assessed without having to assume certain impacts that each form could give.

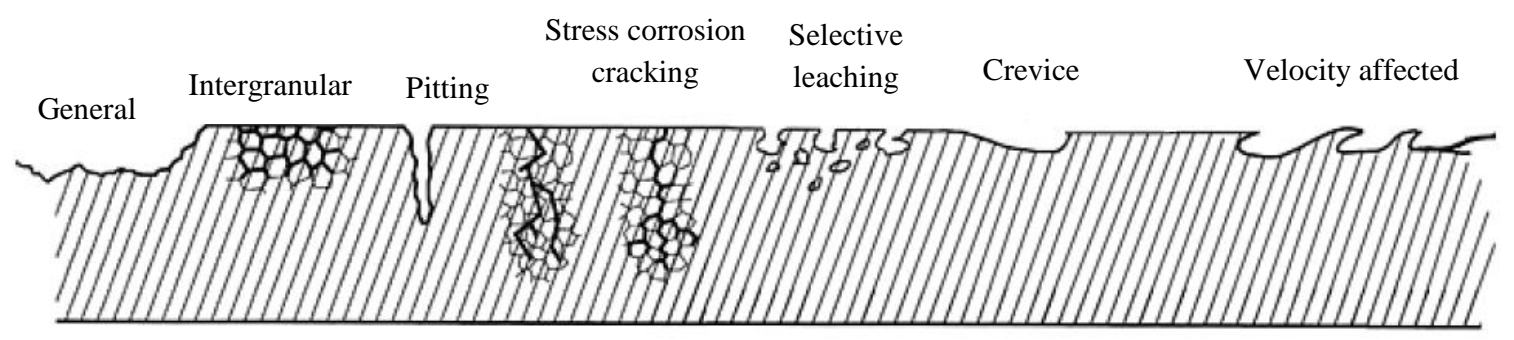

Figure 4. Different forms of corrosion developed on a particular metal surface (Adapted and modified from Freeman [5]). 


\section{Probabilistic physics-of-corrosion}

Corrosion growth evolves with time, spreading in size and increasing in quantities. Most fundamental studies on corrosion science normally are experimental, where the growth of corrosions is critically studied based on a time basis. A work by Rivas et al. [6] and Valor et al. [7] for instance, were focused on experimental investigations on corrosion pits growth with time. In studies on corrosion science such as the works by these authors, it is quite common for a sample of material to be kept under certain controlled environments and later the growth of corrosion colonies would be inspected from time to time. At each inspection, the depth of each corrosion pit would be measured and recorded. Although the results (corrosion depths) for such growth could be made in different ways, presenting them in the form of probabilistic distribution functions (PDF) have been acceptable in describing its characteristics and patterns.

A sample of this presentation could be found in Figure 5, for instance. The figure summarizes (colonies of) corrosion evolvement with time, where at the beginning ( 1 day) the depth is less but becoming deeper by the end (30 days) of the experiment period. Note that the progression of depths is visible from the $x$-axis scale of the graphs. Not only the magnitude of the growth could be seen from here, but also the spread of corrosions. The spread is simply translated by the width of the PDF, indicating the increase in the number of corrosions. While 'new born corrosion' remains on the left tail of the PDF, the 'older' ones would move to the right tail holding deeper corrosion depths.

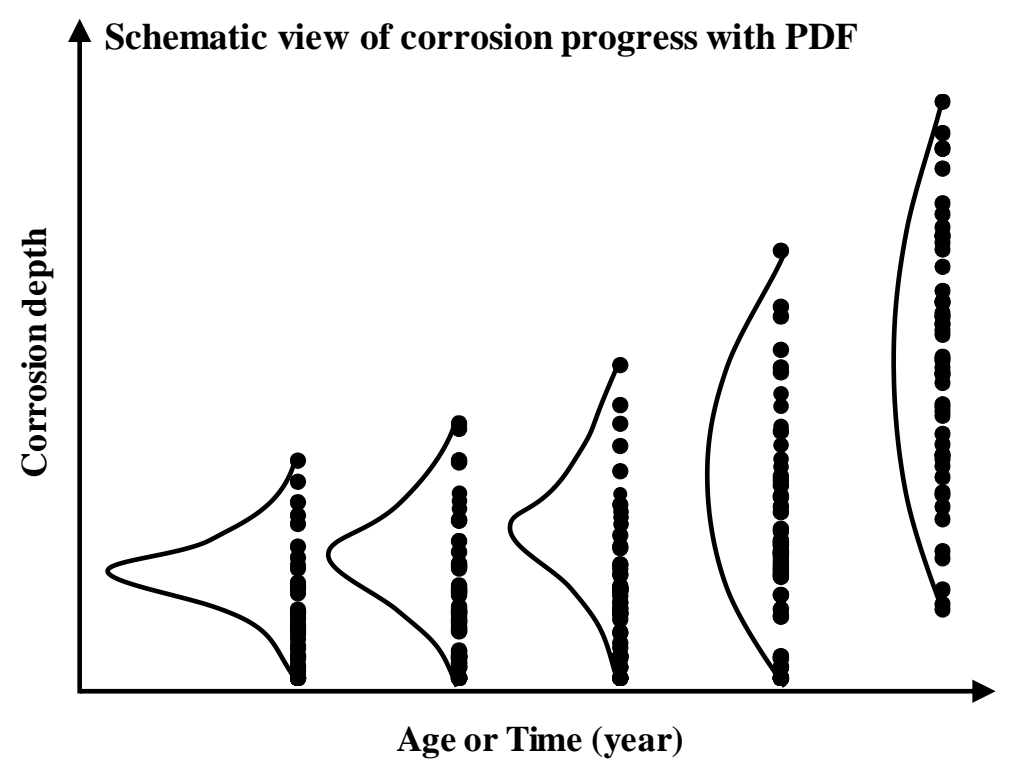

Figure 5. PDF presenting the growth of pit depth over time at different exposure times.

The above representation of PDF has paved the way to describe corrosion as random variables, which eventually allows the data to be interpreted statistically. Insights from the experimental works could then be directly applied to the actual site operations as well, in the present case is pipeline operation. This then conforms well with the scope of the paper, with the analysis projected further towards the reliability assessment of corrosion failures. 


\section{Corrosion models}

It is well recognized that the prediction of the corrosion progress by time is necessary to run our facilities safely. Some studies have been conducted to develop the timedependent corrosion wastage model by many researchers. Among the various types of corrosion shown in Figure 4, the pitting corrosion issue is continually reported by operation side. Recently, Bhandari et al. [8] conducted a wide range of the technical reviews on modelling of pitting corrosion in marine and offshore steel structures. With regard to pitting corrosion of carbon steel pipes, Wang and Melchers [9] conducted indepth investigations.

Paik et al. [10] proposed a simplified technique to estimate the pitting corrosion rate by time which was applied to oil tanker [11] and bulk carrier [12]. Valor et al. (2010) proposed a stochastic approach to pitting-corrosion-extreme modelling based on experimental data. Paik and Kim [13] also proposed an advanced technique to develop time-dependent corrosion wastage model which was applied to oil well tube [14], offshore gas pipeline [15]. Caines et al. [16] also provided in-depth investigations on pitting corrosion literature reviews with modelling techniques on pitting corrosion rate. Recently, Kim et al. [17] proposed a refined technique by adopting a probabilistic approach which was applied to the empirical formulation of current offshore data.

The obtained corrosion models have been widely applied for the ultimate strength-based safety assessment of aged marine structures. A technical review of application studies on ultimate strength analysis of corroded structures has been conducted by Wang et al. [18]. In particular, many researchers have investigated on the degradation of ultimate strength behaviour of ships and offshore structures by considering the time-dependent corrosion damage such as container ship [19], oil tanker [20-23], bulk carrier [24] and fixed jacket platform [25].

\section{Reliability Assessment}

A pipeline system may be exposed to more than one type of failure; however, from the viewpoint of our study, we are concerned with system reliability only in the context of failure due to corrosion. Since the 1990s, researchers have been interested in using probabilistic approaches to assess the reliability of corroded pipelines [26-30]. However, these studies treated pipelines as a single unit and did not segregate the statistical responses of individual pipe segments. Rather, they integrated the existing failure pressure $(\mathrm{PF})$, model. Rather, they integrated the strength/resistance $(\mathrm{R})$ term of the existing failure pressure (PF) model with load (S) term, into a new limit state function (LSF) model. Therein, the equation used for $R$ was mostly modified from PF models that originated from the NG-18 criterion. The NG-18 criterion is a surface flaw equation developed using a semi-empirical fracture mechanics by the NG-18 Line Pipe

Research Committee of the American Gas Association (AGA). Note that all these studies used the same load term, namely the operational loading exerted by the transported hydrocarbon in the pipeline. Also, a few studies have reported on LSF development, a part of which covered the aspects of onshore and buried pipelines [3139].

In the last few years, research focus has shifted to assessing the reliability of pipelines by treating them as a serial system with spatially correlated corrosion defects. De Leon and Macías were among the first to adopt this approach; however, their work simply assumed several degrees of spatial correlation (namely 0.0, 0.2, 0.4, 0.6, 0.8, and 
1.0) for corrosion in certain sections of a pipeline [29]. Zhou later evaluated the timedependent system reliability of a pipeline placed in series that contained multiple active corrosion defects, e.g. small leaks, large leaks, and ruptures [40]. Although it was investigated how the spatial variability of the pressure loading and pipe resistance associated with different defects impacts system reliability, the results suggested that the spatial variability of the pipe properties had a negligible impact on system reliability [40]. Later, Leira et al. studied and quantified system reliability about multiple components with arbitrary correlation levels and independent corrosion defects [41].

Their results showed that the failure probability decreased strongly as the degree of correlation increased; however, it remained unchanged at correlation degrees more than 0.2 . Low values of the correlation coefficient of system-failure probability could be obtained simply by multiplying the failure probability for a single defect by the total number of defects. Simultaneously, Sahraoui et al. [42] developed a maintenance model for inspecting the optimisation of pipelines subjected to external corrosion and exposed to soil conditions, with special consideration given to the spatially varying corrosion rate. Monte Carlo simulations were used to evaluate the failure probability of the serial system.

Various attempts have been made to estimate the reliability of corroded pipelines by treating them either as a single unit or as multiple pipe segments; however, there have been fewer studies on the reliability of pipelines in series. The only work reported to date considered the influence of either different degrees of correlation or different combinations of corrosion defects. The definition of a serial system is somehow closely related to the degree of correlation. When this may be true, different representations of a serial system may also be considered, a part of which is presented in the present work.

\section{METHODOLOGY}

\section{Corrosion Data}

In this paper, corrosion is considered in an operational pipeline in Terengganu, which is located on the east coast of Peninsular Malaysia. The pipeline properties and corrosion information are given in Table 1.

Table 1. Pipeline properties and corrosion information.

\begin{tabular}{ll}
\hline Type: & API 5LX-65 \\
\hline Diameter: & 28 in \\
Nominal wall thickness: & $16.2 \mathrm{~mm}$ \\
Length: & $128.9 \mathrm{~km}$ \\
Year of installation: & 1999 \\
Corrosion inspection year: & 2007 \\
Types of defect: & Internal and external corrosion \\
Number of defects: & 861 defects (554 internal, 307 external) \\
\hline
\end{tabular}

The corrosion data were measured and recorded by a tool known as an intelligent pig (IP); they are presented according to the magnitude and location (orientation) of each defect. The defect magnitude is given by the depth of penetration $(\mathrm{mm})$ or the amount of wall loss concerning pipeline wall thickness (\%). Quite often, 
pipeline operators are more interested in the number of wall losses measured concerning the pipeline wall rather than the longitudinal or circumferential orientations. Thus, data on corrosion defects at depth $d$ are generally given higher priority compared with the longitudinal length $l$ or circumferential width $w$.

\section{Effect of Pipeline Length}

The procedure for analysing the effect of the length of a pipeline system was adapted from a reliability analysis applied to flood- and sea-defence structures and systems [1, 43]. The following assumptions were made.

i. $\quad$ The pipeline system with a total length $L$ is divided into $n$ sections, where $n$ depends on the correlation distance, as shown in Figure 6.

ii. The failure mode (i.e., corrosion) contributes equally to the total failure probability of each pipeline section.

iii. The pipeline has a uniform cross-section along its length $L$.

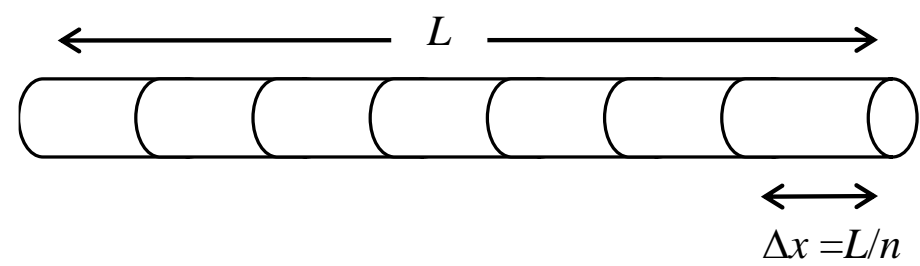

Figure 6. A pipeline of length $L$ divided into $n$ sections (not to scale).

As shown in Figure 6, a pipeline system with a uniform cross-section comprises $n$ sections of a certain length. The strength/resistance $R$ of every pipe section of a serial system can be described as a random variable. We assume that the strengths of two adjacent sections are correlated, with the degree of correlation depending on, among other factors, the distance $\Delta x$ between the two adjacent sections considered.

Statistically, the relationship between the correlation and distance can be described by a correlation function. A common form of an autocorrelation function $\rho$ describing the strength parameter $(R)$ at locations $x$ and $x+\Delta x$ is described by Eq. (5).

$\rho[R(x), R(x+\Delta x)]=e^{-\left(\frac{\Delta x}{d_{\text {corr }}}\right)^{2}}$

where $x$ is the characteristic under consideration, $\Delta x$ is the distance between two points (in time), which is known as the distance lag, $\mathrm{d}_{\text {corr }}$ is the correlation distance, sometimes referred to as the fluctuation scale.

In the context of this study, $\mathrm{x}$ is the corrosion depth $\mathrm{d}$ measured either in millimetres $(\mathrm{mm})$ or as a percentage $(\%)$. From now on, we assume the development of corrosion in a particular pipeline section to be proportional to the corresponding pipeline strength; $d_{\text {corr }}$ is defined as the distance over which the statistical properties of the reliability function are assumed to be completely correlated. Within a statistically homogeneous length of a pipeline, the number of pipeline sections is identified by setting the length of an individual section to $d_{\text {corr. }}$ To continue the analysis, the reliability index $\beta$ for section $i(i=1,2, \ldots n)$, where; 
$P\left(f_{i}\right)=\phi(-\beta)$

is given by

$\beta=\frac{\mu_{\mathrm{R}}-\mu_{\mathrm{S}}}{\sqrt{\sigma_{\mathrm{R}}^{2}+\sigma_{\mathrm{S}}^{2}}}=\frac{\mu_{\mathrm{Z}}}{\sigma_{\mathrm{Z}}}$

where $\phi$ is the standard normal distribution; $\mu$ is the mean and $\sigma$ is the standard deviation. The overall failure probability for a serial structure can be approximated by the Ditlevsen upper bound and is given by:

$P(F)=\phi(-\beta)+(n-1)\left\{\phi(-\beta)+2 \phi(-\beta) \phi\left(-\beta \frac{1-\varrho}{\sqrt{1-\varrho^{2}}}\right)\right\}$

Because;

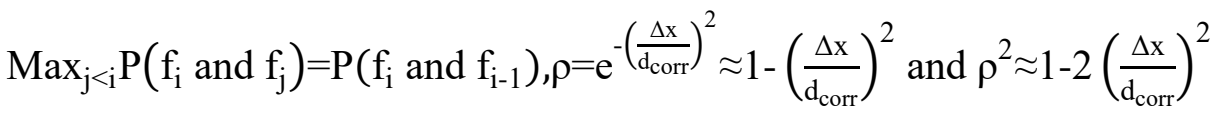

Whereas, for a small,

$\phi(\mathrm{u})=\frac{1}{2}+\frac{\mathrm{u}}{\sqrt{2 \pi}}, \mathrm{P}(\mathrm{F})=\Phi(-\beta)\left\{1+\frac{\mathrm{n}-1}{\mathrm{~d}_{\mathrm{corr}}} \frac{\beta \Delta \mathrm{x}}{\sqrt{\pi}}\right\}$

because $\Delta x=\frac{L}{n}$ and $\frac{\mathrm{n}-1}{\mathrm{nd}_{\text {corr }}} \frac{\beta \mathrm{L}}{\sqrt{\pi}} \rightarrow \frac{\beta \mathrm{L}}{\mathrm{d}_{\text {corr }} \sqrt{\pi}}(\mathrm{n} \rightarrow \infty)$

$\mathrm{P}_{\mathrm{f}}=\Phi(-\beta)\left\{1+\frac{\beta}{\sqrt{\pi}} \frac{\mathrm{L}}{\mathrm{d}_{\text {corr }}}\right\}$

which is independent of the number of sections $n$. Note that $\mathrm{P}_{\mathrm{f}}$ has already been defined as the probability of failure. Also, the final computation of Eq. (10) relies on the predetermined value of $d_{\text {corr }}$; this will be explained further in the next section.

\section{Correlation Distance, $\mathbf{d}_{\text {corr }}$}

Equation (10) can only be used successfully if the correct value of $\mathrm{d}_{\text {corr }}$ is chosen. This can be determined by satisfying both the left-hand side (LHS) and right-hand side (RHS) of Eq. (5). The LHS of Eq. (5) is shown in Eq. (11).

$\rho[R(x), R(x+\Delta x)]$

which corresponds to a standard autocorrelation function that can be computed using a commercial statistical programming language. Herein, the LHS term was evaluated using MATLAB. Meanwhile, the RHS term is shown in Eq. (12). 
$\mathrm{e}^{-\left(\frac{\Delta \mathrm{x}}{\mathrm{d}_{\mathrm{corr}}}\right)^{2}}$

which can be calculated manually once $\mathrm{d}_{\text {corr }}$ is known. Brief guidelines on the procedure for obtaining $\mathrm{d}_{\text {corr }}$ using Eq. (5) are presented below. Recall that the parameter $\mathrm{x}$ is, in fact, the corrosion depth d measured in millimetres $(\mathrm{mm})$ or as a percentage $(\%)$.

Solving the LHS term:

1. Identify the number of sections $\left(\mathrm{n}_{1}, \mathrm{n}_{2}, \ldots \mathrm{n}_{\mathrm{n}}\right)$ of the pipeline from which the size/distance $\Delta \mathrm{x}$ can be determined.

2. Compute the average corrosion depth at each section $n_{i}$, i.e., $d_{1}, d_{2}, \ldots d_{n}$.

3. Evaluate the autocorrelation function for $d_{1}, d_{2}, \ldots d_{n}$ at each pipeline section using the standard statistical command in MATLAB.

4. Store the results for subsequent comparison.

Solving the RHS term:

1. Use step 1 to determine the values of $\mathrm{n}$ and $\Delta \mathrm{x}$.

2. Assume an initial value for $\mathrm{d}_{\text {corr. }}$.

3. Calculate the RHS term manually and store the result.

4. Compare the result obtained from step 7 with the corresponding one from step 4.

5. Repeat steps 6-8 for another value of $d_{\text {corr }}$ until the results from steps 4 and 7 agree sufficiently.

Basically, Eq. (5) is solved using trial and error for different values of $d_{\text {corr. }}$ The best value of $\mathrm{d}_{\text {corr }}$ is the one that minimises the sum of the squares of the errors (SSE). If this task is conducted graphically, the graphs representing the LHS and RHS of Eq. (5) should approximate each other closely.

\section{RESULTS AND DISCUSSION}

It is noted earlier that computing $\mathrm{P}_{\mathrm{f}}$ using in Eq. (10) relies on predetermining the value of $d_{\text {corr. }}$ Thus, we begin this section by considering how to determine $d_{\text {corr }}$ and then describe the method to use that value to compute $\mathrm{P}_{\mathrm{f}}$.

\section{Determination of $d_{c o r r}$}

We consider two different numbers of sections, namely $n=13$ (scenario 1 ) and 128 (scenario 2), as given in Table 2. Fixing the number of sections then provides the corresponding value of $\Delta x$ because $\Delta x=L / n$, where $L$ is the pipeline length. A random trial value of $d_{\text {corr }}$ was selected for each scenario $\left(d_{\text {corr }}=85 \mathrm{~km}\right.$ and $65 \mathrm{~km}$ for scenario 1 and 2, respectively) and applied to Eq. (5). Following this, the LHS and RHS terms of Eq. (5) were calculated and plotted in a single graph. Because the process to visually compare the agreement between these two terms is complicated, we used SSE instead. As mentioned earlier, SSE measures the difference between the LHS and RHS terms and determines the potential source of error causing the difference. A small SSE is always preferable because in this case, the RHS and LHS of Eq. (5) are in better agreement. In this study, $\mathrm{d}_{\text {corr }}=85 \mathrm{~km}$ gave a smaller SSE value of 0.034 as compared to $2.424\left(\mathrm{~d}_{\text {corr }}=65 \mathrm{~km}\right)$ and was used in the next step of the calculation.

Nevertheless, the SSE value obtained in scenario 2 was fairly acceptable. It would not be out of place to propose a certain range of values of the correlation distance $d_{c o r r}$ for the pipeline structure, as was done for other structures, e.g., a flood-defence 
system [44]. Thus, given the characteristic similarities between a flood-defence system and the pipeline in question, we propose representing the latter with a $d_{c o r r}$ of $65-85 \mathrm{~km}$.

Table 2. Two scenarios for computing the correlation distance $\mathrm{d}_{\text {corr }}$.

\begin{tabular}{ccccc}
\hline Scenario & $\begin{array}{c}\text { Number of } \\
\text { sections, } \mathrm{n}\end{array}$ & $\begin{array}{c}\Delta \mathrm{x} \\
(\mathrm{km})\end{array}$ & SSE & $\begin{array}{c}\text { Correlation distance } \\
\mathrm{d}_{\text {corr }}(\mathrm{km})\end{array}$ \\
\hline 1 & 13 & 10 & 0.034 & 85 \\
2 & 128 & 1 & 2.424 & 65 \\
\hline
\end{tabular}

While assuming and choosing the correct $\mathrm{d}_{\text {corr }}$ value for the candidate pipeline API 5LX-65, it was interesting to notice the effect of the number of sections on the autocorrelation functions. Figure 8 and 10 provide a better view on this aspect. Selecting fewer sections (scenario 1) led to a relatively consistent pattern. This was because the defects had been grouped at reasonable intervals $(\Delta x)$, for which the corresponding mean values were within a relatively small range of $1.0-1.6 \mathrm{~mm}$, as shown in Figure 7. This promoted fairly smooth autocorrelation functions, as can be seen in Figure 8. In contrast, having a large number of sections (scenario 2) tended to depict the actual corrosion distribution along the whole length of the pipeline. As such, any significant or insignificant (i.e., extremum) defect characteristics were taken into account, preventing them from simply being ignored (i.e., through averaging). The mean values computed in scenario 2 shown in Figure 9 seem to fall within 0-2.6 mm, which is a wider range than that obtained in scenario 1; moreover, the corresponding autocorrelation functions result in fluctuating and "peaky" trends illustrated in Figure 10.

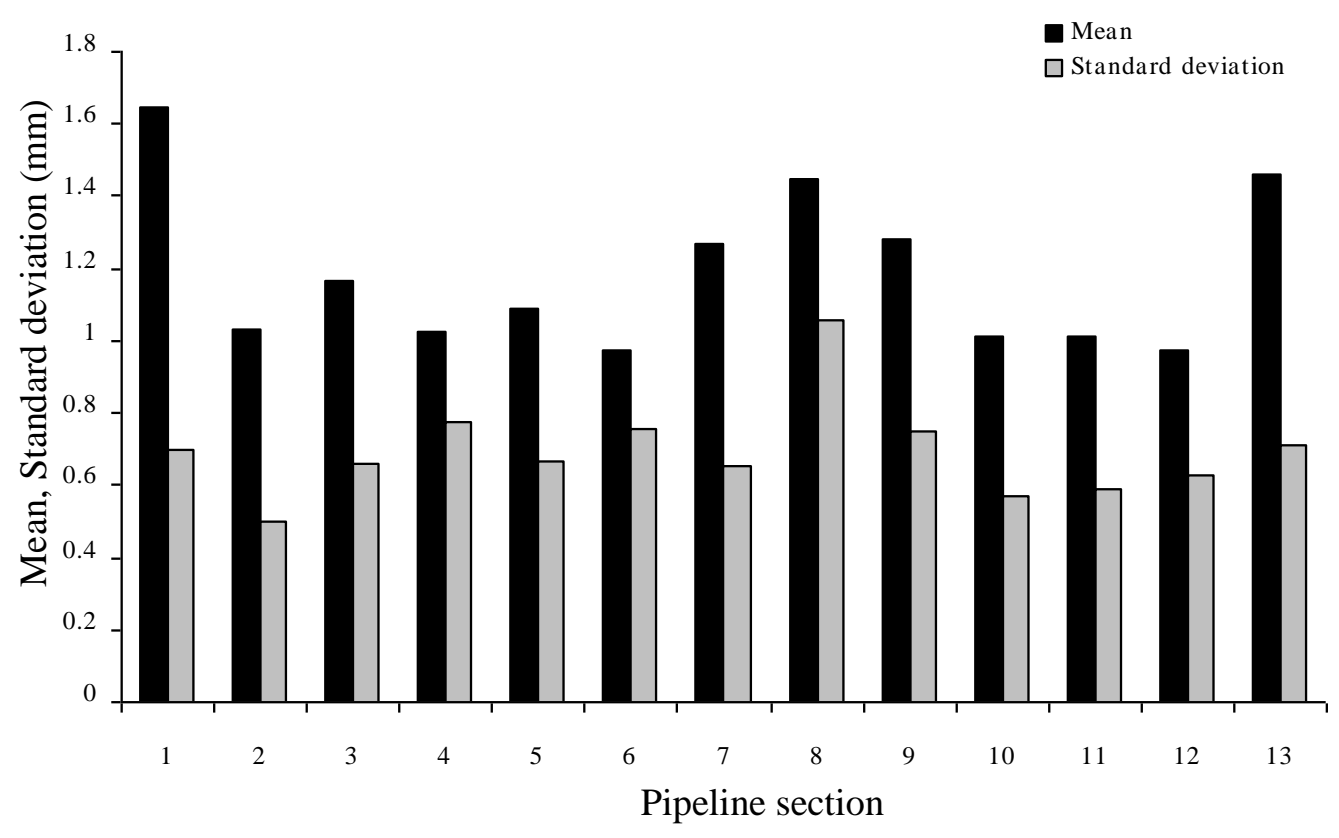

Figure 6. Mean and standard deviation for the pipeline divided into 13 sections. 


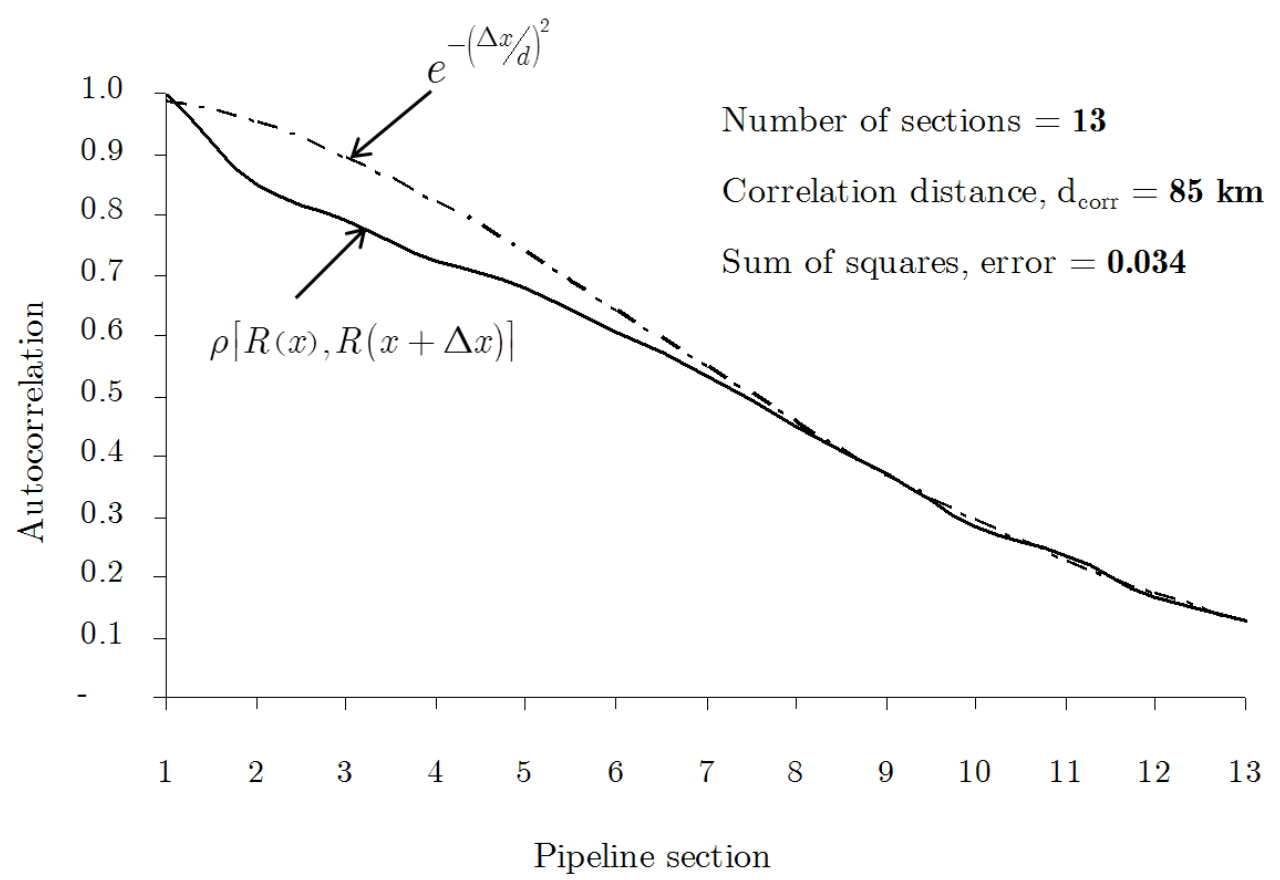

Figure 7. Autocorrelation functions for the pipeline divided into 13 sections.

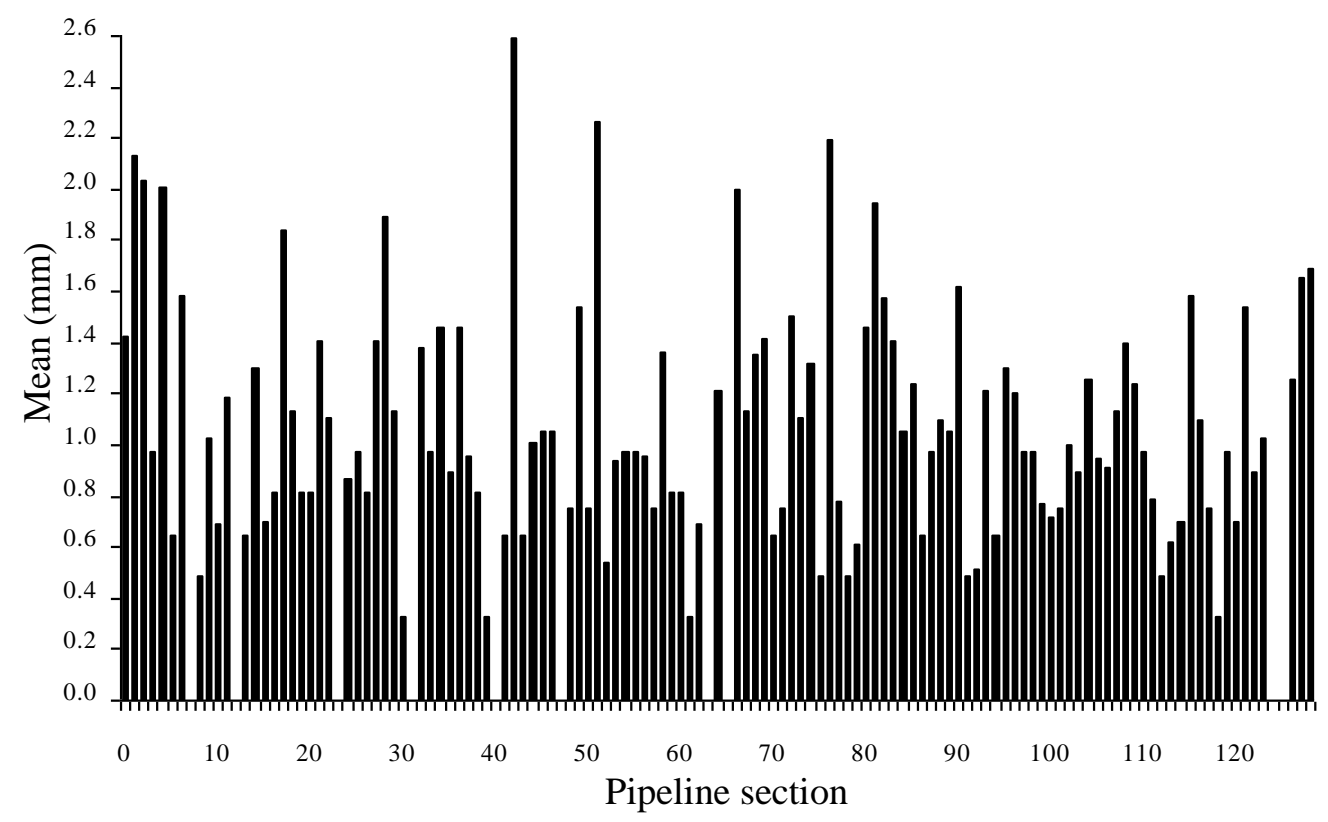

Figure 8. Mean for the pipeline divided into 128 sections. 


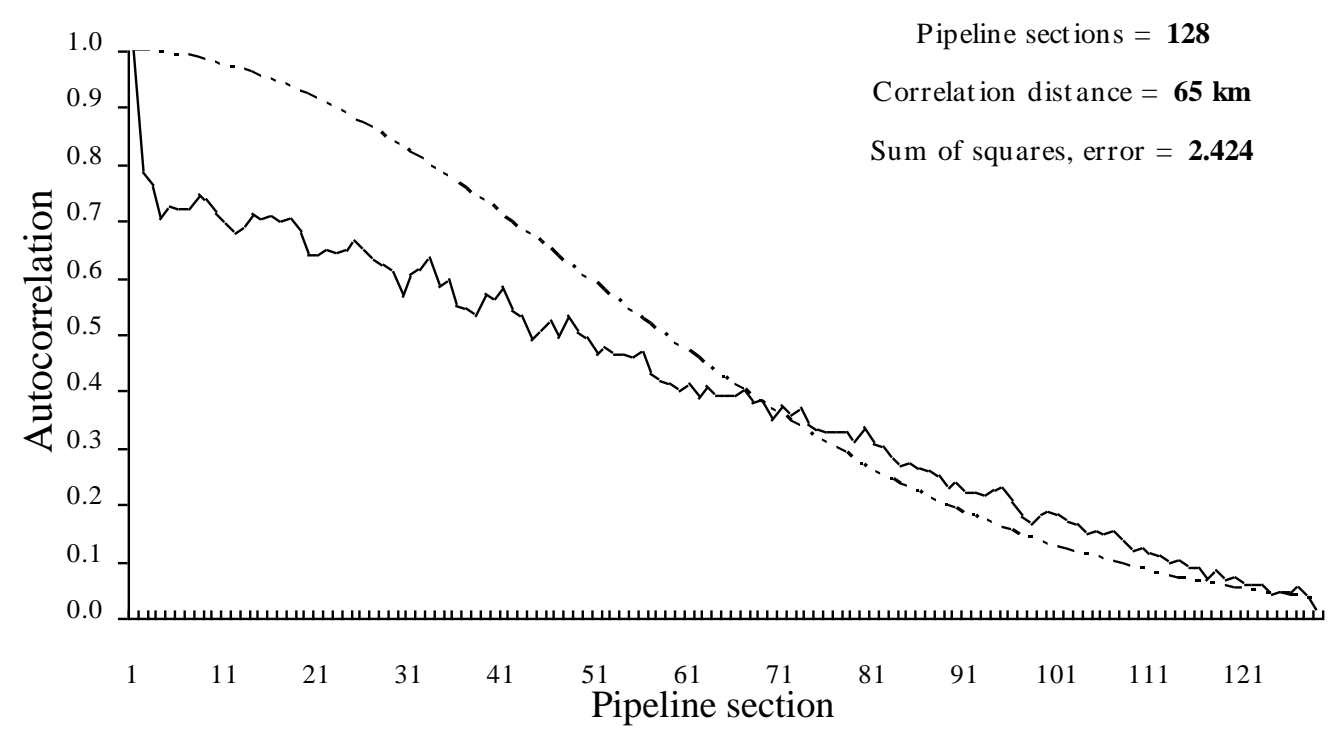

Figure 9. Autocorrelation functions for the pipeline divided into 128 sections.

\section{Determination of Failure Probability, $\boldsymbol{P}_{\boldsymbol{f}}$}

For the sake of illustration, we assumed a correlation distance $\mathrm{d}_{\text {corr }}=85 \mathrm{~km}$ for the remaining analysis described in this section. This value was then applied to Eq. (10) to complete the analysis of length effects. Different loading values (i.e., operating pressures) were applied to the equation, which produced different $\mathrm{P}_{\mathrm{f}}$ values, as shown in Figure 11.

For comparison, we used a different reliability model called the "dimensionless limit state function" [45]. This is given by Eq. (13) and is computed in the absence of sectional length effects, as plotted in Figure 11.

$\mathrm{Z}=\left[\left(\frac{\mathrm{t}}{\mathrm{D}}\right)_{\text {Resistance }}^{0.8442\left(\frac{\mathrm{d}}{\mathrm{t}}\right)^{-0.0545}\left(\frac{1}{\mathrm{w}}\right)^{-0.0104}}\right] \underbrace{\frac{\mathrm{P}_{\mathrm{o}}}{\mathrm{SMTS}}}_{\text {Load }}$

Where $P_{o}$ is the operating pressure, SMTS is the specified minimum tensile strength, $t$ is the pipeline wall thickness, $\mathrm{D}$ is the diameter, $\mathrm{d}$ is the corrosion depth, 1 is the longitudinal corrosion length and; $w$ is the circumferential corrosion width.

It is worth noting here that a typical limit-state function, given by Eq. (13), comprises two important terms: resistance and load. When generated and evaluated statistically, these terms represent the remaining strength of the corroded pipeline through the value previously defined as $\mathrm{P}_{\mathrm{f}}$. We recommend that the interested readers refer to the original paper by Mustaffa et al. for further details on the development of Eq. (13) [45]. Here, we are content to show in Figure 12 the sensitivity of each parameter used in Eq. (13). This implies that $\mathrm{D}$ and $\mathrm{t}$ are the most important variables in the reliability model given by Eq. (13), followed by SMTS of the pipeline material. The negative sensitivity of $\mathrm{P}_{\mathrm{o}}$ implies that the structure is prone to failure under high loads. Through these findings, the effect of each parameter was later presented through the 
final values of $P_{f}$ obtained under different dimensionless loading conditions ( $\left.P_{o} / S M T S\right)$, as shown in Figure 11.

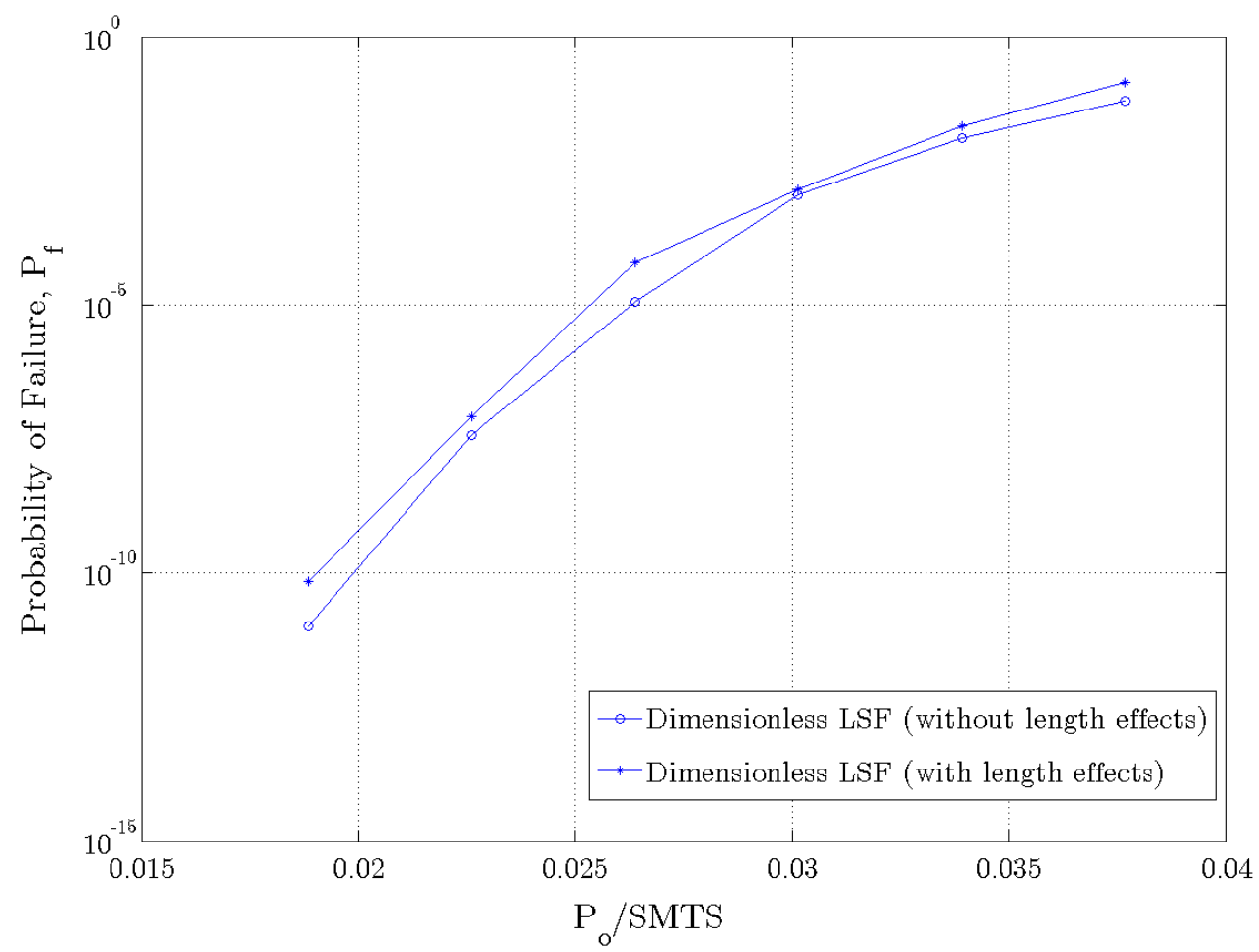

Figure 11. Failure probability $\mathrm{P}_{\mathrm{f}}$ determined for the API 5LX-65 pipeline with Eq. (10) and without Eq. (13) length effects.

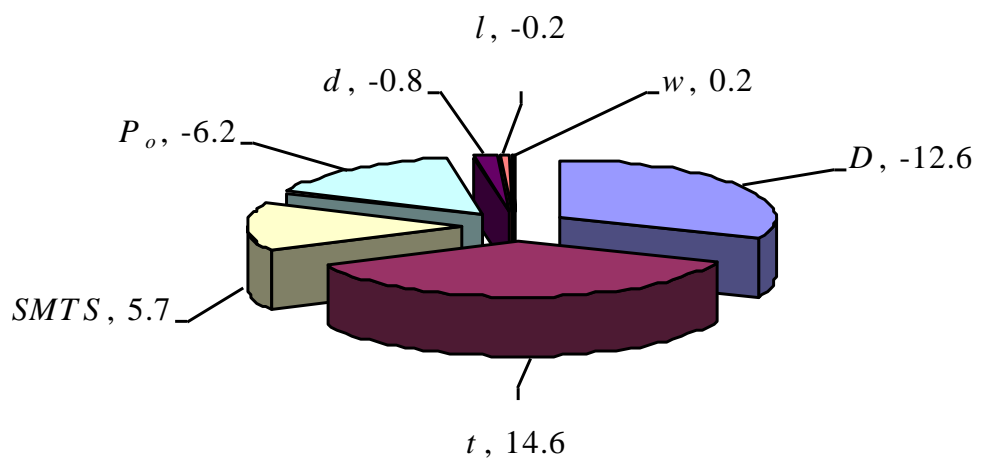

Figure 12. Degree of sensitivity of the parameters.

Figure 11 shows that the pipeline reliability model that considers the influence of length effects in Eq. (10) produces a higher probability of failure than the one that excludes these effects as in Eq. (13). Despite the close agreement between the two models, it is important to note that we expect a higher reliability value when the strengths of two adjacent sections of a corroded pipeline are assumed to be correlated. This is true for any structure operated serially because failure in one section might lead to failures in the adjacent sections. Hence, relying solely on the governing parameters affecting corrosion in a pipeline as given in Eq. (13) is not entirely correct when 
estimating the reliability of the structure. Instead, a proper reliability estimation using the model proposed in Eq. (10) is necessary for better prevention of failure due to leaks.

\section{CONCLUSION}

The outcomes of this research are useful in that they provide pipeline operators with different options for managing their corroded pipelines. Tackling the problem by dividing the pipeline into sections may be economical and practical if the threat is considered to be moderate. However, if reliability along the entire length of the pipeline becomes a major concern, our findings suggest performing analysis while considering length effects. This method seems to represent a worse scenario (i.e., higher $\mathrm{P}_{\mathrm{f}}$ ) when compared with the one that excludes length effects.

A cluster of interacting defects may pose a greater risk of pipeline failure. This is because corrosions in different segments of a pipeline placed in series are considered to be correlated; this can be described probabilistically using an autocorrelation function. Determining the value of $d_{\text {corr }}$ enables a pipeline to be analysed in sections for which the statistical properties of the reliability function are correlated. Depending on their concerns and limitations (e.g., budget, manpower, and resources), pipeline operators may apply one of the proposed approaches to determine the reliability of the pipeline structure.

\section{ACKNOWLEDGEMENT}

This research was supported by the Technology Innovation Program (Grant No. 10053121) funded by the Ministry of Trade, Industry \& Energy (MI, Korea). The authors are also grateful for the support provided by POSTECH, POSCO, Daewoo E\&C, Republic of Korea and Universiti Teknologi PETRONAS (UTP), Malaysia.

\section{REFERENCES}

[1] van Gelder PHAJM, Buijs F, Mai van C, ter Horst W, Kanning W, Nejad M, Gupta S, Shams R, van Erp N, Gouldby B, Kingston G, Sayers P, Wills M, Kortenhaus A, Lambrecht HJ. Reliability analysis of flood sea defence structures and systems Appendices 1 to 5. Research Report (No. T07-08-02), FLOODsite, Brussels, UK; 2008 (www.floodsite.net).

[2] Mai van C. Probabilistic design of coastal flood defences in Vietnam. PhD Dissertation, Delft University of Technology, The Netherlands; 2010.

[3] Vrijling JK. Probability in civil engineering. Delft: Delft University of Technology Publications; 2006.

[4] Ang AHS, Tang WH. Probability concepts in engineering planning and design. Vol. II: Decision, risk, and reliability. New York: John Wiley and Sons; 1984.

[5] Freeman SR. Corrosion-related failures. In: Becker WT, Shipley RJ, editors. ASM Handbook Volume 11: Failure Analysis and Prevention. Novelty: ASM International; 2002.

[6] Rivas D, Caleyo F, Valor A, Hallen JM. Extreme value analysis applied to pitting corrosion experiments in low carbon steel: Comparison of block maxima and peak over threshold approaches. Corrosion Science 2008; 50(11): 31933204. 
[7] Valor A, Caleyo F, Rivas D, Hallen JM. Stochastic approach to pittingcorrosion-extreme modelling in low-carbon steel. Corrosion Science 2010; 52(3): 910-915.

[8] Bhandari J, Khan F, Abbassi R, Garaniya V, Ojeda R. Modelling of pitting corrosion in marine and offshore steel structures - A technical review. Journal of Loss Prevention in the Process Industries 2015; 37: 39-62.

[9] Wang X, Melchers RE. Long-term under-deposit pitting corrosion of carbon steel pipes. Ocean Engineering 2017; 133: 231-243.

[10] Paik JK, Kim SK, Lee SK. Probabilistic corrosion rate estimation model for longitudinal strength members of bulk carriers. Ocean Engineering 1998; 25(10): 837-860.

[11] Paik JK, Lee JM, Hwang JS, Park YI. A time-dependent corrosion wastage model for the structures of single- and double-hull tankers and FSOs and FPSOs. Marine Technology 2003a; 40(3): 201-217.

[12] Paik JK, Thayamballi AK, Park YI, Hwang JS. A time-dependent corrosion wastage model for bulk carrier structures. International Journal of Maritime Engineering 2003b; 145(A2): 61-87.

[13] Paik JK, Kim DK. Advanced method for the development of an empirical model to predict time-dependent corrosion wastage. Corrosion Science 2012; 63: 5158.

[14] Mohd Hairil M, Paik JK. Investigation of the corrosion progress characteristics of offshore subsea oil well tubes. Corrosion Science 2013; 67: 130-141.

[15] Mohd Hairil M, Kim DK, Kim DW, Paik JK. A time-variant corrosion wastage model for subsea gas pipelines. Ships and Offshore Structures 2014; 9(2): 161176.

[16] Caines S, Khan F, Shirokoff J. Analysis of pitting corrosion on steel under insulation in marine environments. Journal of Loss Prevention in the Process Industries 2013; 26(6): 1466-1483.

[17] Kim DK, Wong EWC, Lee EB, Yu SY, Kim YT. 2018. A method for the empirical formulation of current profile. Ships and Offshore Structures, in-press (https://doi.org/10.1080/17445302.2018.1488340).

[18] Wang Y, Wharton JA, Shenoi RA. Ultimate strength analysis of aged steelplated structures exposed to marine corrosion damage: A review. Corrosion Science 2014; 86: 42-60.

[19] Kim DK, Park DK, Kim HB, Seo JK, Kim BJ, Paik JK, Kim MS. The necessity of applying the common corrosion addition rule to container ships in terms of ultimate longitudinal strength. Ocean Engineering 2012; 49: 43-55.

[20] Kim DK, Park DK, Kim JH, Kim SJ, Kim BJ, Seo JK, Paik JK. Effect of corrosion on the ultimate strength of double hull oil tankers - Part I: stiffened panels. Structural Engineering and Mechanics 2012; 42(4): 507-530.

[21] Kim DK, Park DK, Park DH, Kim HB, Kim BJ, Seo JK, Paik JK. Effect of corrosion on the ultimate strength of double hull oil tankers - Part II: hull girders. Structural Engineering and Mechanics 2012; 42(4): 531-549.

[22] Kim DK, Kim BJ, Seo JK, Kim HB, Zhang XM, Paik JK. Time-dependent residual ultimate longitudinal strength - grounding damage index (R-D) diagram. Ocean Engineering 2014; 76: 163-171.

[23] Kim DK, Kim HB, Zhang XM, Li CG, Paik JK. Ultimate strength performance of tankers associated with industry corrosion addition practices. International Journal of Naval Architecture and Ocean Engineering 2014; 6(3): 507-528. 
[24] Kim DK, Kim SJ, Kim HB, Zhang XM, Li CG, Paik JK. Ultimate strength performance of bulk carriers with various corrosion additions. Ships and Offshore Structures 2015; 10(1): 59-78.

[25] Kim DK, Zalaya MA, Mohd Hairil M, Choi HS, Park KS. Safety assessment of corroded jacket platform considering decommissioning event. International Journal of Automotive and Mechanical Engineering 2017; 14(4): 4462-4485.

[26] Ahammed M, Melchers RE. Reliability estimation of pressurized pipelines subject to localised corrosion defects. International Journal of Pressure Vessels and Piping 1996; 69(3): 267-272.

[27] Pandey MD. Probabilistic models for condition assessment of oil and gas pipelines. NDT\&E International 1998; 31(5): 349-358.

[28] Ahammed M. Probabilistic estimation of remaining life of a pipeline in the presence of active corrosion defects. International Journal of Pressure Vessels and Piping 1998; 75(4): 321-329.

[29] De Leon D, Macías OF. 2005. Effect of spatial correlation on the failure probability of pipelines under corrosion. International Journal of Pressure Vessels and Piping 2005; 82(2): 123-128.

[30] Teixeira AP, Guedes Soares C, Netto TA, Estefen SF. 2008. Reliability of pipelines with corrosion defects. International Journal of Pressure Vessels and Piping 2008; 85(4): 228-237.

[31] Ahammed M, Melchers RE. Reliability of underground pipelines subjected to corrosion. Journal of Transportation Engineering 1994; 120(6): 989-1002.

[32] Ahammed M, Melchers RE. Probabilistic analysis of pipelines subjected to pitting corrosion leaks. Engineering Structures 1995; 17(2): 74-80.

[33] Ahammed M, Melchers RE. Probabilistic analysis of underground pipelines subjected to combined stresses and corrosion. Engineering Structures 1997; 19(12): 988-994.

[34] Guan XL, Melchers RE. A load space formulation for probabilistic finite element analysis of structural reliability. Probabilistic Engineering Mechanics 1999; 14(1-2): 73-81.

[35] Caleyo F, Gonzalez JL, Hallen JM. A study on the reliability assessment methodology for pipelines with active corrosion defects. International Journal of Pressure Vessels and Piping 2002; 79(1): 77-86.

[36] Lee OS, Pyun JS, Kim DH, Hwang SW, Cho KS. Effect of boundary conditions of failure pressure models on reliability estimation of buried pipelines. Key Engineering Materials 2004; 261-263: 803-808.

[37] Lee SM, Chang YS, Choi JB, Kim YJ. 2006. Probabilistic integrity assessment of corroded gas pipelines. Journal of Pressure Vessel Technology 2006; 128(4): 547-555.

[38] Santosh A, Vinod G, Shrivastava OP, Saraf RK, Ghosh AK, Kushwaha HS. 2006. Reliability analysis of pipelines carrying $\mathrm{H}_{2} \mathrm{~S}$ for risk based inspection of heavy water plants. Reliability Engineering \& System Safety 2006; 91(2): 163170.

[39] Khelif R, Chateauneuf A, Chaoui K. Reliability-based assessment of polyethylene pipe creep lifetime. International Journal of Pressure Vessels and Piping 2007; 84(12): 697-707.

[40] Zhou W. 2010. System reliability of corroding pipelines. International Journal of Pressure Vessels and Piping 2010; 87: 587-595. 
[41] Leira BJ, Naess A, Næss OEB. Reliability of corroded pipelines accounting for system effects. The $12^{\text {th }}$ International Conference on Applications of Statistics and Probability in Civil Engineering (ICASP 2015), 12-15 July, Vancouver, Canada; 2015.

[42] Sahraoui Y, Chateauneuf A, Khelif R. Reliability-based maintenance optimization of pipelines considering space-variant corrosion rate. The $12^{\text {th }}$ International Conference on Applications of Statistics and Probability in Civil Engineering (ICASP 2015), 12-15 July, Vancouver, Canada; 2015.

[43] van Gelder PHAJM, Vrijling JK. Probabilistic design in hydraulic engineering. Delft: Delft University of Technology Publications; 2002.

[44] Vrouwenvelder ACWM, Vrijling JK. Probability in civil engineering. Delft: Delft University of Technology Publications; 2006.

[45] Mustaffa Z, van Gelder PHAJM. A review and probabilistic analysis of limit state functions of corroded pipelines. The $20^{\text {th }}$ International Offshore and Polar Engineering Conference (ISOPE 2010), 20-25 June, Beijing, China; 2010. 